\title{
As CIÊNCIAS SOCIAIS: ENTRE A AVALIAÇÃo E A RELEVÂNCIA
}

\author{
Michel Nicolau NETTO*
}

RESUMO: O sistema de avaliação de pós-graduação garantiu que as pesquisas científicas nas universidades públicas brasileiras se mantivessem resistentes às ameaças que frequentemente sofrem. Contudo, quanto mais hegemônico se tornou esse sistema, mais os pesquisadores transformaram suas regras na própria noção de relevância científica, esvaziando a capacidade das ciências sociais influenciarem outros campos do saber. Neste artigo analiso esse processo e busco notar como ele leva, paradoxalmente, à perda da autonomia do campo das ciências sociais em função da importância que assumem a mídia e o clamor por pesquisas mais utilitárias. Concluirei defendendo a autonomia do campo das ciências sociais e da universidade pública, mas por outros meios, que recoloquem suas capacidades em atuarem no mundo, deformando os campos da ordem.

PALAVRAS-CHAVE: Ciências sociais. Autonomia. Sistema de avaliação. Cientometria.

Hoje é comum que intitulemos nossos trabalhos com a expressão em tempos de crise e o título deste texto apropriadamente poderia ser: Ciências sociais em tempo de crise. A noção de crise parece ter se tornado uma condição total sob a qual estamos todos vinculados. Contudo, sempre quando penso na crise, tilinta em minha mente que a universidade pública claudica, mas continua em pé, e que nós, cientistas sociais, ainda estamos aqui. Vivemos em tempos de crise, mas como é notável a capacidade das ciências sociais resistirem no Brasil. Dessa forma, talvez a pergunta mais importante seja: como é possível, em meio a tantos ataques, que

\footnotetext{
UNICAMP - Universidade Estadual de Campinas. Instituto de Filosofia e Ciências Humanas. Campinas - SP - Brasil. 13081-970 - mnicolau@unicamp.br. https://orcid.org/0000-0003-0893-971X.
} 
ainda consigamos resistir? A resistência só ocorre porque construímos um sistema universitário público forte, dentro do qual as ciências sociais possuem armas para manterem sua própria forma de regulação. Usando termos mais bourdieusianos, resistimos porque construímos um campo autônomo, capaz de refratar os agentes e as regras de outros campos que a todo tempo tentam se impor. É essa condição de nossa resistência e por isso penso que a maior ameaça que sofremos é dirigida à autonomia do sistema universitário e das ciências sociais, mais especificamente.

Vou aqui deter-me nas ciências sociais e analisar algumas dessas ameaças. A primeira ameaça está na própria forma como o campo das ciências sociais vem se estruturando recentemente: o sistema de avaliação, um dos instrumentos centrais para a autonomia, está, na verdade, minando a própria relevância das ciências sociais. As outras duas ameaças são externas ao campo e se alimentam justamente daquilo que o mina por dentro: penso na mídia e no clamor por uma ciência social mais utilitária. Concluirei defendendo a autonomia das ciências sociais e da universidade pública brasileira, mas por outros meios, com outras armas, que recoloquem o peso e a capacidade das ciências sociais em atuarem no mundo, deformando os campos da ordem.

\section{$* * *$}

Um dos principais meios que garantiu a autonomia das ciências sociais foi o bem-sucedido sistema de pós-graduação no Brasil. Com o parecer Sucupira de 1965 o Estado brasileiro reconheceu e regulamentou a pós-graduação no país e a tornou parte de uma política estatal ordenada (MARTINS, 2000). Sua implementação se deu em um período ditatorial militar, nacionalista e desenvolvimentista. Embora isso tenha indicado a partir da década de 1970, especialmente com a criação do Conselho Nacional de Desenvolvimento Científico e Tecnológico (CNPq) em 1975, um privilégio às áreas mais próximas de garantir o desenvolvimento científico e tecnológico (BALBACHEVSKY, 2005), as ciências humanas também se expandiram. Isso se nota pelo fato de que até meados dos anos 2000 a maioria dos cursos de pós-graduação no Brasil era na área de humanas e, com isso, seus pesquisadores se utilizaram do peso, mesmo demográfico, que tinham na pós-graduação brasileira e garantiram recursos substanciais às suas pesquisas, possibilitando o avanço da área (BALBACHEVSKY, 2005).

O resultado dessa política pode ser visto na evolução dos números da pósgraduação brasileira. Em 1965, no ano do parecer Sucupira, o Conselho Nacional de Educação (CNE) reconheceu 38 cursos de pós-graduação: 27 mestrados e 11 doutorados. Quando o $\mathrm{CNPq}$ foi fundado, esse número havia passado para 578 cursos: 429 de mestrado e 149 de doutorado. Em 2002, eram 2.347: 1.506 de mestrado e 841 de doutorado (BALBACHEVSKY, 2005). Esse número não 
parou mais de crescer: em 2015 havia 5.333 cursos, sendo 3.238 de mestrado e 2.095 de doutorado no Brasil. Em termos de praticantes, enquanto em 2002 foram diplomados 23 mil mestres e 6.800 doutores, em 2015 foram 46.517 novos mestres e 18.625 novos doutores no Brasil ${ }^{1}$. Os cursos de pós-graduação em sociologia e ciências sociais não ficam atrás nessa expansão: em 1998 esses cursos somavam 29 programas de mestrado e doutorado, enquanto em 2016 esse número passou para 54.

Quanto mais a pós-graduação se expandia mais se tornava necessária a ordenação dos dados e sua catalogação. Renato Ortiz (2008) mostra que a cientometria se desenvolve na década de 1960, nos Estados Unidos, com essa intenção e que nas décadas seguintes vai se tornar a base de avaliação da produção intelectual em todo mundo. A questão central que ali se colocava era: em meio a um mar de pesquisadores e pesquisas, como se diferencia aquilo que realmente deve ser lido daquilo que deve se manter à margem? De Solla Price (apud ORTIZ, 2016, p. 43), um dos iniciadores da cientometria, ainda se perguntava como medir um "corpo científico de conhecimento que possa se tornar a base de políticas que governos e cidadãos possam requerer". Seria necessário, portanto, quantificar, mas também hierarquizar, dois verbos centrais que fundam a noção de avaliação contemporânea. A citação, nesse contexto, ganha importância e legitimidade. Contudo, não é apenas ser citado que importa, mas ser citado em revistas centrais, pois só elas poderiam garantir que o trabalho citado é, de fato, meritório. Dessa forma, um primeiro passo é classificar as revistas e, a partir de suas classificações, poder afirmar a relevância do que é publicado e citado. Daí a mágica se forma: sem que se tenha que ler nada do que está escrito pode-se avaliar e classificar qualquer pesquisa e qualquer pessoa; basta, para tanto, que se saiba onde está publicada e onde publica quem a cita. A lógica é circular: como eu publico em tais revistas de onde parte a maior parte das citações, eu me qualifico; ao mesmo tempo, porque eu - qualificado como aquele que publico em revistas qualificadas e citado em revistas qualificadas - publico nessas revistas, eu as qualifico. Bourdieu $(1987$, p.2) dizia que "agentes são ambos classificados e classificantes, mas eles se classificam de acordo com (ou dependendo de suas posições nas classificações)". Nada demonstra isso melhor do que aqui descrevo.

Em meados dos anos 2000, também no Brasil se desenvolve uma "nova era de avaliação, [...], marcada [...] pela introdução de mecanismos mais precisos de mensuração, especialmente da produção bibliográfica" (ADORNO \& RAMALHO, 2018, p.28), algo que busca tornar mais objetiva a avaliação dos programas. A Coordenação de Avaliação de Pessoal de Nível Superior (CAPES) a adotou para o desenvolvimento de política pública que desse conta de avaliar a capacidade dos programas em formar bem. Para tanto, ela tomou como pressuposto, centralmente,

\footnotetext{
1 Relatório da Comissão de Acompanhamento Programa Nacional de Pós-Graduação (PNPG). Documento interno.
} 
a avaliação da produção intelectual dos docentes, medida pela qualidade do suporte da publicação, e não pelo próprio conteúdo do que se publica. Assim, mede-se a qualidade de um artigo pela nota recebida pela revista; de uma publicação em livro, especialmente pela editora em que é publicado. Em 1998, a CAPES introduziu o sistema que atribui notas aos programas (de 3 a 7), fiando-se em larga medida, na avaliação da produção do corpo docente e condicionando os recursos financeiros dos programas à sua nota. Desse momento em diante, a produção intelectual se tornou vinculada a um sistema avaliativo desse tipo, com maior ou menor impacto, mas sempre presente na vida de todos nós que habitamos o mundo acadêmico ou que somos a ele pretendentes. Isso se deu em larga medida pela complacência dos membros da comunidade científica e, em especial, das ciências sociais. Em primeiro lugar porque a própria lógica de avaliação foi em larga medida desenvolvida por cientistas sociais, como Robert Merton não nos deixa esquecer (apud ORTIZ, 2008). Ainda, porque o organograma do sistema de avaliação CAPES é todo formado por membros da comunidade científica, e são os próprios coordenadores dos programas que em suas áreas (como a sociologia) produzem o documento que norteia toda a avaliação. Isto é, a questão central não é compreender como as agências de fomento impõem regras de avaliação, mas sim como as condutas dos próprios pesquisadores se moldam por essas regras e, a partir dessa moldura, condicionam suas próprias noções sobre a produção intelectual.

Dessa forma, entendo que o que caracteriza esse sistema de avaliação a que hoje estamos submetidos é o compartilhamento de uma crença, que se refere à necessidade de se avaliar e, subsidiariamente a isso, a uma série de suposições, tais quais: a de que só existe o que é avaliável, de que há critérios objetivos para a avaliação, de que boa avaliação é sinônimo de qualidade, de que se pode avaliar a partir de pressupostos, tal qual a medição da qualidade de um artigo pela revista em que é publicado. Eu não quero aqui, discutir os critérios usados em sistemas de avaliação específicos ${ }^{2}$. Por isso, este artigo não é sobre CAPES ou CNPq em si, mas sobre algo anterior: a autoridade que esse sistema de avaliação assume para conduzir as condutas dos pesquisadores e, assim, ser determinante na formação do campo atual das ciências sociais.

Não deixemos de reconhecer que o sistema de avaliação fortaleceu a autonomia do campo no Brasil. Justamente o fortalecimento da avaliação a partir dos periódicos atuou nesse sentido. Segundo relatam os representantes da área de sociologia entre 2005 e 2010, "nossa atuação (...) ocorreu no sentido de reconhecer o papel relevante dos periódicos na divulgação do trabalho científico e na importância da avaliação por pares como forma de garantir um grau de isenção na escolha dos

\footnotetext{
2 Para mais esclarecimento ler a crítica de uso das estatísticas em avaliação de Adler, Ewing e Taylor (2009).
} 
artigos a serem publicados" (ADORNO \& RAMALHO, 2018, p.31). A relação entre artigos e pares é o centro do sistema de avaliação. Em primeiro lugar, porque os artigos publicados nas revistas que lhe atribuem as notas são selecionados a partir de pareceres dos pares. Em segundo lugar, porque as revistas mais valorizadas são aquelas mais voltadas para os pares. Em outras palavras, valoriza-se mais aquilo que é produzido para os próprios pares e se desvaloriza o que é produzido para os não pares, sendo essa a noção básica de autonomia para Bourdieu (1997, p.88): quanto mais autônomo um campo, mais "os produtores têm por clientes apenas seus concorrentes, os que teriam podido fazer em seu lugar a descoberta que eles lhes apresentam".

A classificação dos periódicos entre A1 e C separa os suportes de publicação entre aqueles que são voltados para o meio acadêmico e os que são voltados para um público amplo. No caso da sociologia, a partir do estrato B3 se exige que o periódico seja:

[...] publicado por instituição com Pós-Graduação stricto sensu, ou Sociedade Científica de âmbito nacional ou internacional reconhecida pela Coordenação de Área, ou por Instituição Profissional de âmbito nacional, ou Instituição de Pesquisa, ou ser publicada com apoio da CAPES, CNPq ou financiamento estatal com avaliação por pares, ou estar disponível em pelo menos uma base de dados ou indexador internacional distinto daqueles especificados nos estratos seguinte. (BRASIL, 2017, p.14).

Conforme sobe a avaliação do periódico, mais restrito ao campo acadêmico se exige que o mesmo seja. A partir do estrato B1, limite a partir do qual a área de sociologia considera as publicações como qualificadas, exige-se um conselho editorial formado por "especialistas reconhecidos, de origem nacional e internacional, devidamente identificados na publicação, evitando a concentração institucional" (BRASIL, 2013, p.16).

Dessa forma, como os artigos são pontuados nas avaliações de acordo com o ranking das revistas, e os maiores rankings são das revistas mais propriamente voltadas para os pares, os pesquisadores são inclinados - e, dependendo de suas posições no campo, o correto seria dizer forçados - a voltarem as suas publicações a essas revistas e, consequentemente, a seus pares. No documento da área de sociologia de 2016, celebrava-se que:

É possível observar uma clara tendência de maior qualificação da produção em periódicos, com dois movimentos simultâneos: maior qualificação dos periódicos a partir da adoção dos critérios que definem os estratos superiores do Qualis da área e, ao mesmo tempo, o aumento significativo do número de artigos direcionados para periódicos qualificados (Qualis B1 e superior). (BRASIL, 2016, p.6) 
É reveladora nesse sentido, a comparação da produção de artigos da avaliação CAPES 2013 com dados de três anos, entre 2010 e 2012 - período 1 (BRASIL, 2013) e a avaliação CAPES 2017 que apresenta dados de quatro anos, 2013 e 2016 período 2 (BRASIL, 2017), na área de sociologia. No período 1 havia 52 programas, enquanto no período 2 eram 54. O número de artigos publicados variou em 55,91\%, com 8.059 artigos no período 2, contra 5.169 artigos no período 1. Além do grande crescimento da produção neste tipo de suporte, destaca-se o fato de que ele se concentrou especialmente nos extratos A1 e A2. No período 1 foram publicados 493 artigos A1, contra 891 no período 2, o que significa uma variação de 80,73\%. Somados A1 e A2 a variação entre os períodos chega a 107,68\%, 703 artigos A1 e A2 no período 1. Em 2010 houve uma diminuição no número de produções no extrato B5, com uma queda de $52 \%{ }^{3}$.

Tabela 1: Comparação da produção de artigos segundo avaliações CAPES 2013 (2010-2012, Período 1) e CAPES 2017 (2013-2016, Período 2)

\begin{tabular}{|c|c|c|c|c|c|c|c|c|c|c|c|c|c|c|}
\hline & \multirow{2}{*}{$\begin{array}{c}\text { Dados do } \\
\text { PPG }\end{array}$} & \multicolumn{10}{|c|}{ Bibliográfica } \\
\cline { 2 - 12 } & Artigos & \multicolumn{10}{|c|}{ Artigos completos publicados em periódicos técnico-científicos } \\
\hline $\begin{array}{l}\text { Ano } \\
\text { base }\end{array}$ & $\begin{array}{c}\text { Número de } \\
\text { programas }\end{array}$ & Total & A1 & A2 & B1 & B2 & B3 & B4 & B5 & C & NC & NP & A1+A2 & A1+A2+B1 \\
\hline 2017 & 53 & 8059 & 891 & 569 & 970 & 638 & 882 & 1506 & 515 & 401 & 0 & 676 & 1460 & 2430 \\
\hline 2013 & 52 & 5169 & 493 & 210 & 660 & 540 & 422 & 676 & 1091 & 844 & 233 & 0 & 703 & 1363 \\
\hline
\end{tabular}

Fonte: Elaboração própria a partir de relatórios da Plataforma Sucupira.

Com a crescente concorrência entre os programas nos esforçamos para nos adequar às normas dessa concorrência, ou seja, para internalizar em nossa própria atividade as lógicas da avaliação. Desse modo, surge o problema: quanto mais nos adequamos à avaliação, mais ela se torna o império da ordenação da área e adquire uma autoridade que ultrapassa sua própria função.

A primeira questão a se perguntar - e repito, não estou preocupado aqui em discutir os critérios de avaliação - é: para que serve a avaliação? Do ponto de vista estritamente formal e geral, serve para que o governo, principal investidor dos recursos em pesquisa, produza um conhecimento sobre o desempenho das áreas e dos programas. Contudo, a avaliação acaba servindo como critério para se pensar o próprio trabalho intelectual. Em outras palavras, uma avaliação que serve para uma política pública é utilizada como forma de se dizer aquilo que é válido ou não, bom ou ruim, dentro do campo das ciências sociais. Lembremos da mágica

3 Dados públicos, que podem ser encontrados na página da Plataforma Sucupira: Disponível em: <https://sucupira.capes.gov.br/sucupira/>. 
da cientometria: medir qualquer produção e qualquer pessoa sem que alguém (com exceção dos pareceristas) tenha que ler qualquer produção intelectual. Não quero discutir se isso é um problema para o desenvolvimento de políticas públicas, mas que isso é um grande problema no momento em que é usado como um substituto a outras formas de se avaliar a qualidade de um trabalho como, por exemplo, a boa e velha leitura. Interessante é notar que o sistema é todo baseado na avaliação dos pares, mas ao se tecnicizar essa avaliação ficam os pares dispensados de fazerem suas próprias avaliações. Crê-se no sistema de avaliação e se tornam absolutos seus critérios. Dessa forma, surgem as distorções.

Um pesquisador carrega em si o peso da nota de seu programa, uma vez que a forma como ele é visto pelos pares é condicionada a essa nota. Não vamos admitir isso publicamente, mas um pesquisador percebe imediatamente o que digo quando seu programa cai ou sobe de nota: se cai, olhares desconfiados; se sobe, tapinha nas costas para o autor de um trabalho que, de repente, ficou melhor. O mesmo ocorre com a qualidade de um artigo que é medida pela nota de um periódico, pois, como critica Antonio Ozaí da Silva (2009, p. 120), “em tese a qualidade do que é produzido é garantida pela qualidade do periódico que veicula". Um biólogo brasileiro, pesquisador da Universidade de Brasília (UnB), notou um aumento na quantidade de artigos brasileiros publicados na base de dados aberta Scimago Institutions Rankings, elevando a posição brasileira de $20^{\circ}$ para $13^{\circ}$ país que mais publica no mundo. Contudo, afirma o pesquisador, não se pode confundir quantidade com qualidade, e em termos de qualidade o Brasil vem perdendo posição, uma vez que os artigos daqui são pouco citados. Soando um credo mundial, então afirma o pesquisador que "a melhor forma de analisar a qualidade de um conjunto grande de artigos é por meio das suas citações" (MORAES, 2017, n.p.). Ou seja, toma-se um critério de avaliação (a citação), pela própria noção de qualidade.

Mas pensemos nesse sentido em referência à bola da vez, a internacionalização. Como afirma Cynthia Sarti (2015), há muito do que fazemos que não se pode avaliar. Eu diria que um dos aspectos mais importantes do sistema atual de avaliação, que é a internacionalização, não é avaliável. Isso se dá, em primeiro lugar, porque as relações de força existentes no campus global, como diria David Logde (2011), produz um abismo na condição de impacto da produção científica entre os pesquisadores de diferentes países. Não vou detalhar algo que Renato Ortiz (2016) demonstrou de maneira inquestionável: a possibilidade de influência da produção acadêmica está diretamente ligada com o lugar de sua produção e com a língua de sua publicação. Dou apenas alguns dados para desenvolver o argumento. Entre 1990 e 1992, 56\% da produção indexada em sociologia se deu em revistas publicadas nos Estados Unidos. Mais importante do que isso, contudo, $76 \%$ das citações feitas de periódicos ocorreram em textos publicados nessas revistas norte-americanas (Wolfgang Glänzel apud ORTIZ, 2008). Para se ter uma ideia, 0,8\% das citações 
ocorreram de textos publicados em periódicos na França. A concentração sobe mais ainda se pensamos na língua e, aí, o inglês predomina. Diz-se que o inglês é a língua franca da globalização, mais ainda da ciência. Ou seja, é um código que todos compartilhamos. Apliquemos essa noção às traduções e pensemos: qual a língua para a qual mais se fazem traduções? Oras, se o inglês é a língua franca, esperase que seja para essa língua que se destine a maior parte das traduções. Ocorre, contudo, algo bem diferente. Atualizando um dado que Ortiz (2008) usou, me volto ao Index Translationum ${ }^{4}$ para demonstrar que entre 1979 e 2017 a principal língua de destino de títulos de livros foi o alemão, com 301.935 publicações. A ela segue o francês (240.045), o espanhol (228.559 títulos) e, só então, o inglês com 164.509 títulos. Em compensação, a língua de origem, a partir da qual a tradução é feita, mostra outro cenário. Agora, o inglês aparece em primeiro lugar, muitíssimo na frente das outras línguas: foram traduzidos do inglês 1.266.110 publicações. Em segundo lugar aparece o francês, com apenas 226.123 publicações; o alemão segue em terceiro (208.240) e o russo em quarto (103.624). O inglês sozinho ultrapassa todas as outras línguas em termos de origem de traduções. Isso significa que o inglês não opera como língua franca das ciências, mas como a língua de autoridade. Supõese que aquilo que se publica em inglês é simplesmente mais importante para se ler, se citar, se traduzir.

Tabela 2: Traduções entre 1979 e 2017 segundo o Index Translationum

\begin{tabular}{|c|c|c|c|}
\hline \multicolumn{4}{|c|}{ Traduções entre 1979 e 2017 } \\
\hline Língua de destino & $\begin{array}{c}\text { Quantidade } \\
\text { (em títulos) }\end{array}$ & Língua de origem & $\begin{array}{c}\text { Quantidade } \\
\text { (em títulos) }\end{array}$ \\
\hline Alemão & 301.935 & Inglês & 1.266 .110 \\
\hline Francês & 240.045 & Francês & 226.123 \\
\hline Espanhol & 228.559 & Alemão & 208.240 \\
\hline Inglês & 164.509 & Russo & 103.624 \\
\hline
\end{tabular}

Fonte: Tabela de autoria própria elaborada com dados do Index Translationum, Unesco.

As condições globalmente desiguais de publicação e citação torna provincianos os critérios adotados para medição de internacionalização, ou seja, por incomparáveis, cada lugar adota formas de medi-la, sem que os dados sejam relevantes quando comparados internacionalmente. Por exemplo, no documento da área de Sociologia, (BRASIL, 2017), na seção destinada à internacionalização afirma-se que:

\footnotetext{
4 Index Translationum é uma compilação das traduções publicadas anualmente que são fornecidas pelas bibliotecas nacionais dos países membros da United Nations Educaional, Scientif and Cultural Organization (UNESCO). Disponível em: <http://www.unesco.org/xtrans/>. Acessado em: 17 mai. 2019.
} 
[...] a avaliação dos programas 6 e 7 teve seu foco as parcerias e acordos que estabelecem relações acadêmicas simétricas entre o Brasil e demais países, bem como o papel de liderança e nucleação que os Programas de Excelência demonstram na formação de quadros para a Sociologia e as Ciências Sociais. Levou-se em conta, ainda, a inserção em instituições científicas, nacionais e internacionais, bem como prêmios de reconhecimento por liderança e destaque acadêmico na área. (BRASIL, 2017, p.33)

O documento indica que a internacionalização,

[...] está presente, ainda, na atração de alunos de pós-graduação a partir do Programa de Estudantes-Convênio de Pós-Graduação (PEC-PG) da Capes e também de países fora do programa, o aumento de cotutelas, especialmente com países europeus, e incorporação de estudantes de diversas nacionalidades. (BRASIL, 2017, p.33).

Por fim, ele destaca a ampliação da inserção da área "no cenário internacional por meio do crescimento da produção em periódicos e livros, premiações internacionais (...)" (BRASIL, 2017, p.33).

Nota-se que, em geral, a noção de internacional operada se baseia naquilo que está fora de um país, Brasil, mas localizado em outro. Aí surge um problema: isso só é positivo se aquilo que está no destino representa ganho para o que está na origem. Dessa forma, publicar em revistas estrangeiras conta no Brasil para se dizer que um programa brasileiro é internacionalizado. Contudo, como se viu, as revistas mais citadas se concentram nos Estados Unidos da América e, nesse sentido, haveria razão de se aplicar esse critério para um norte-americano, para quem publicar no estrangeiro significa publicar em revistas de menor impacto? Da mesma forma, diante da quantidade de convênios e acordos com universidades estrangeiras, também um importantíssimo sinal de internacionalização de um programa, seria mais importante para uma universidade dos Estados Unidos um convênio com uma universidade brasileira do que com seus, assim digamos, pares? Quando coordenador de pós-graduação em sociologia na Universidade Estadual de Campinas (Unicamp) fechei um convênio com a Columbia University. Alguns dias depois, por coincidência, visitava a Unicamp um representante dessa universidade e, assim, me chamaram para lhe dar boas-vindas. Eu me apresentei, ele mencionou o convênio, e eu lhe contei que aquilo não era nada demais, já que a Unicamp possuía mais de 300 convênios internacionais. A Columbia, ele disse, "possui pouquíssimos convênios internacionais". Seria, assim, uma universidade brasileira, com suas centenas de convênios - boa parte inoperantes, mas que mesmo assim somam pontos - e com docentes que publicam no estrangeiro, mais internacional do que a Columbia? 
É evidente que nas principais universidades americanas, assim como naquelas de algumas nações europeias, um índice importante para a internacionalização é a atração de estudantes estrangeiros. Influentes, essas universidades pautam um dos principais rankings de classificação de universidades no mundo, o QS World University Rankings ${ }^{5}$, no qual internacionalização conta 10\% da nota. Essa parcela da nota é então dividida em dois critérios com 5\% para cada: a razão de staff internacional (international faculty ratio) e a razão de estudantes internacionais (international student ratio). Não se fala de convênios ou publicações internacionais, como tanto se pesa na avaliação brasileira. Por aqui, ao contrário, embora se cite a quantidade de alunos e docentes estrangeiros nos critérios de avaliação, essa pouco pode contar, porque os números são, de fato, irrisórios uma vez que o número de alunos estrangeiros em nossas universidades federais não chega a $1 \%$, na Universidade de São Paulo (USP) que lidera, o número não chega a 3,5\% (TOLEDO; MARQUES, 2018).

A questão não é criticar os critérios, mas mostrar que elas são, de toda forma, implausíveis, e esse fato não é menor quando vemos o que significam os critérios usados pelo QS. Pelo critério de número de alunos e staff estrangeiros, as universidades localizadas em países com pouca base de estudantes nacionais, mas com forte atração de estrangeiros, se destacam a frente daquelas localizadas em países de maior tradição acadêmica, mas de alta base de estudantes e staffs nacionais. Assim, a universidade líder no ranking de internacionalização pelo critério de estudantes estrangeiros é o Institut Européen d'Administration des Affaires (INSEAD), uma escola de negócios com campi em Fointanebleau (França), Singapura e Abu Dhabi, e que possui 100\% de seus 1.031 estudantes estrangeiros. Já a universidade líder em internacionalização pelo critério de profissionais estrangeiros é a American University in Dubai (AUD), onde todos seus 144 profissionais são estrangeiros. Interessante que o INSEAD não é sequer classificado no ranking geral e só aparece, em segundo lugar, no ranking específico de business \& management studies. A AUD está classificada no ranking geral, mas entre as posições 561-570.

De fato, há pouca relação entre a posição geral no ranking da QS e a posição de internacionalização das universidades. As universidades norteamericanas, que lideram as quatro primeiras posições do ranking geral, despencam na internacionalização, especialmente porque possuem uma larguíssima base de alunato nacional e, dessa forma, uma baixa proporção de alunos estrangeiros. As universidades inglesas, que ocupam as posições de 5 a 8 no ranking geral, também despencam em termos de internacionalização, contudo por razões diferentes das universidades americanas: com uma população de estudantes nacionais menor,

5 QS World University Rankings são classificações universitárias anuais publicadas pela Quacquarelli Symonds (QS) do Reino Unido. Disponível em: <https://www.topuniversities.com/university-rankings/ world-university-rankings/2018>. Acessado em 18 mai 2019. 
o alunato estrangeiro tem forte presença; contudo, há proporcionalmente poucos professores estrangeiros.

Tabela 3: World University Rankings - 2018

\begin{tabular}{|c|c|c|c|c|}
\hline $\begin{array}{c}\text { Posição } \\
\text { geral }\end{array}$ & $\begin{array}{c}\text { Nome da } \\
\text { Universidade }\end{array}$ & País & $\begin{array}{c}\text { Posição } \\
\text { em estafe } \\
\text { estrangeiro }\end{array}$ & $\begin{array}{c}\text { Posição } \\
\text { em Aluno } \\
\text { estrangeiro }\end{array}$ \\
\hline 1 & MIT & EUA & 36 & 70 \\
\hline 2 & Stanford & EUA & 54 & 177 \\
\hline 3 & Harvard & EUA & 103 & 165 \\
\hline 4 & Caltech & EUA & 126 & 106 \\
\hline 5 & Cambridge & Reino Unido & 87 & 57 \\
\hline 6 & Oxford & Reino Unido & 68 & 50 \\
\hline 7 & UCL & Reino Unido & 102 & 20 \\
\hline 8 & $\begin{array}{l}\text { Imperial College } \\
\text { London }\end{array}$ & Reino Unido & 42 & 12 \\
\hline 9 & University of Chicago & EUA & 218 & 149 \\
\hline 10 & ETH Zurich & Suíça & 14 & 47 \\
\hline
\end{tabular}

Fonte: Tabela de autoria própria elaborada com dados da Quacquarelli Symonds (QS).

A internacionalização pode ser uma boa intenção, mas não pode ser comparada, pois os condicionantes envolvidos e as realidades nacionais são muito diversas. Há outra razão, porque o que importa da internacionalização não gera índice. Ianni (2006, p. 13) dizia que "a globalização assusta e encanta", e ele se encantava com as possibilidades para o pensamento:

Quando se trata da problemática global, o sujeito do conhecimento é desafiado a deslocar o seu olhar por muitos lugares e diferentes perspectivas, como se estivesse viajando pelo mapa do mundo. As exigências da reflexão implicam a adoção de um 'olhar desterritorializado', capaz de mover-se do indivíduo à coletividade, caminhando por povos e nações, tribos e nacionalidades, grupos e classes sociais, culturas e civilizações. Um olhar desterritorializado movendo-se através de territórios e fronteiras, atravessando continentes, ilhas e arquipélagos (IANNI, 1998, p. 5).

Na verdade, a globalização proporcionou não apenas a oportunidade de desterritorialiazarmos o olhar, como propõe Ianni (1998), mas também de nos 
localizarmos em reduzidas redes globais, nas quais convivemos com pensamentos muito parecidos com os nossos, nas quais nos portamos como aqueles que Renato Ortiz (2008) chamou de provincianos globais. A tentativa de se medir a internacionalização nos induz a isso. Ávidos em busca dos critérios usados nas avaliações, tendemos a nos internacionalizar sem nos desterritorializarmos. Afinal, se preciso publicar em revistas internacionais, é mais fácil contar com um colega que pensa como eu e propor a ele uma colaboração. Querendo aumentar a presença de estrangeiros no campus, melhor convidar um professor que já faz parte de minha rede. Alguns de nossos colegas viajam muito, vivem em congressos, suas ideias, contudo, se tornam cada vez mais fixas. Eles estão satisfeitos, assim como os coordenadores de seus programas, afinal, aparecerão bem nas medições. Contudo, o olhar desterritorializado, esse não será medido, pois não pode ser medido.

A confusão entre avaliação, sob critérios de uma política específica, e a relevância da pesquisa, do pesquisador ou da universidade toma uma dimensão ainda mais problemática quando a avaliação se torna índice de autoridade para diversas atividades que nada têm a ver com o objetivo da avaliação. Como mostra Danilo Martucelli (2015), a quantofrenia torna os indicadores hegemônicos. A questão a notar é que muito embora a avaliação dos programas se volte a uma política científica, com objetivos próprios, seus indicadores passam a ser usados por agentes e atividades bastante distantes disso. Vemos isso por todo lado. A Unicamp usa a nota CAPES dos programas de pós-graduação como um dos três índices que definem a quantidade de bolsas de estágio discente que cada unidade receberá. Qual a relação entre a nota e isso? Colegas de cursos de economia e administração - embora seja algo certamente presente em outros cursos que desconheço - contam como o preço de suas consultorias para empresas e agências internacionais variam conforme as notas de seus programas, isso digamos, de modo oficial. Contudo, por trás dos panos é mais perverso. Colegas muitas vezes nos chamam para propor mesas, fóruns, etc. porque a chance de aprovação é maior quando o nome de um programa de alta nota aparece na proposta. Quando isso ocorre, o sistema de avaliação deixa de se voltar para seu fim e se torna, ele próprio, a forma como a área se organiza. Não digo que haja uma intenção deliberada dos organismos responsáveis pelos sistemas de avaliação, como a CAPES, nesse sentido. Contudo, se a produção intelectual de um tempo só pode ser compreendida a partir da análise das condições de possibilidades de sua produção, devemos entender que a importância que adquirem os sistemas de avaliação vigentes - que condicionam os recursos que teremos para pesquisa, as oportunidades que teremos para apresentar nossos trabalhos, as bolsas que nossos alunos terão - faz com que moldemos a imagem que hoje temos do trabalho intelectual de acordo com as expectativas dos próprios sistemas de avaliação.

Parece-me que um dos casos mais evidentes em que isso se opera é na perda da frequência da produção de livro, ou melhor, de pesquisas que originam um 
livro. A comparação entre o triênio 2010 - 2012 e o quadriênio 2013 - 2016 é interessante, mas nos mostra pouco. O que nos mostra é que na área de concentração em sociologia houve um aumento de $46,81 \%$ no número de publicações organizadas sob a rubrica livros, o que inclui obra completa, capítulo de livros, verbetes e outros. Seria mais interessante saber é se estamos publicando mais ou menos obras integrais, mas isso não é possível, porque na última avalição, ao contrário daquela do triênio 2010 - 2012, havia apenas a categoria obra completa, englobando coletâneas e obras integrais. Para que pudéssemos diferenciar uma da outra seria preciso consultar cada uma das 1.777 obras completas citadas na última avaliação, algo que não sou capaz de fazer. Dessa forma, escolhi olhar para um programa de excelência (nota 6 ou 7), o que significa que tomo para análise um programa em que há correspondência entre sua produção e as expectativas da avaliação. O exercício se mostrou interessante, pois com um corpus de análise manuseável pude consultar o Currículo Lattes dos autores e obter um conhecimento maior sobre o que publicaram. Excluí duas das obras completas listadas, pois não consegui encontrar informações precisas sobre elas. Das que restaram, observa-se que metade das obras completas é publicação em livro de teses (33\%) e dissertações (17\%); $25 \%$ são organização de coletâneas; $20,83 \%$ são livros integrais de pesquisas diferentes do resultado de mestrado ou doutorado. Restam, ainda, 4,17\% das obras que são traduções de livros anteriormente publicados em português. No grupo dos livros integrais publicados diferentes de resultado mestrado ou doutorado (os que somam 20,83\%), predominam entre os autores aqueles que se doutoraram há mais tempo. Em verdade, apenas uma obra daquele programa foi publicada por alguém que se doutorou neste século, mesmo assim trata-se do co-autor do livro, sendo que o outro co-autor - pertencente a outro programa - também se doutorou no século passado. Em relação aos outros livros desse grupo, o autor que se doutorou mais recentemente o fez em 1991 e o que se doutorou há mais tempo o fez em $1979^{6}$.

Isso pode indicar que a publicação em livro integral é algo de uma geração mais antiga ou de quem acaba de se formar. Poucos de nós que estamos no início ou na metade de nossas carreiras publicamos, ao menos pelos dados do programa estudado, nossas pesquisas na forma de um livro. Isso não se dá porque não achamos mais o livro importante (como ocorre em outras áreas) ou mesmo porque o livro não conta na avaliação (de fato, ele conta). Publicamos menos nossas pesquisas em livros, porque o tempo do livro não cabe no tempo da avaliação de nossos programas. O tempo da avaliação é imediato, não podemos passar um ano sem publicar. O tempo do livro é mais longo, depende de pesquisa que muitas vezes demora, depois de uma escrita que muitas vezes não pode obedecer a lógica anual

6 Dados sobre nome dos livros são encontrados na página da Plataforma Sucupira: https://sucupira. capes.gov.br/sucupira/. O procedimento utilizado, após a identificação dos livros, foi olhar o Currículo Lattes de cada autor. 
em que somos inseridos. Ianni (1998) gostava de falar em emblema. Eu diria que o livro é o emblema do trabalho intelectual de duas ou três gerações anteriores à minha, hoje, o emblema é o artigo ou, para esnobar, o paper. O fato de que não podemos esperar muito para publicar tem implicações também na dificuldade imensa que hoje um pesquisador tem de mudar de objeto de pesquisa. Ouvi certa vez de um colega: "não aguento mais torcer o meu objeto para ver se dali sai outro artigo". Adorei essa expressão: estamos torcendo nossos objetos, tal qual fazemos com uma pasta de dente na busca de um resto que sirva por mais uma noite. O tempo da avaliação nos exige pressa, e não dá para esperar o tempo de se construir um novo objeto.

A questão, portanto, não é que estamos simplesmente nos especializando, no sentido que pensaria Weber (2016). A questão é que estamos nos repetindo, recortando em cada vez mais finas fatias de nossos objetos. Fazemos assim porque trocamos o tempo da ciência pelo tempo da avaliação.

A consequência disso é que quanto mais somos obrigados a torcer nossos objetos e a produzir para nossos pares, cada vez mais estamos perdendo a condição de que nosso campo influencie os outros campos. Quando se olha para a noção de campo de Bourdieu (1983) apenas do ponto de vista estrutural se perde um elemento central: o poder e a disputa. Os campos não são apenas percebidos a partir de seu grau de refração, mas estão inseridos em relações de poder nas quais os agentes de um campo se esforçam em deformar outros campos a partir das regras de seu campo. Falei muito no termo de relevância, pois aqui me expresso como eu a penso: relevante é a pesquisa que contribui para seu campo ao ponto de fortalecê-lo para deformar outros campos. Isso não é a mesma coisa que dizer que devemos produzir mirando externamente ao campo das ciências sociais. Em verdade, afirmo o oposto: devemos pensar a pesquisa como forma de tornar o campo das ciências sociais forte o suficiente para deformar os outros campos. Quando deixamos de publicar livros, quando nos preocupamos apenas com os números que nossos trabalhos geram, quando torcemos nossos objetos para buscar mais uma gota que se torne um novo artigo A1, quando apenas nos voltamos para nossos pares, nós tornamos a ciência que fazemos, em nossos próprios termos, menos relevante.

$$
* * *
$$

A frustração que muitos de nós temos em não sermos lidos (ou sermos pouco lidos), em não sermos ouvidos revela a fragilidade do campo das ciências sociais hoje. Incapazes de usarmos nossos próprios meios como forma de interferir na sociedade, estamos cada vez mais permeáveis às forças externas ao nosso campo. Penso nessas forças como ameaças externas à autonomia do campo e aqui cito duas.

A primeira delas é a mídia. Hoje os intelectuais interferem no debate público quando saem de nosso campo, quando se empenham na mídia e nas redes sociais. 
Quando argumento dessa maneira, quero afirmar que nossos intelectuais-celebridades possuem um genuíno desejo, propriamente intelectual, de interferir no debate público. É por isso que sou muito mais compreensivo com eles do que Bourdieu (1997) foi com aqueles que chamou de intelectuais heterônomos, que viviam em debates rasos na televisão francesa. Ali se está mais próximo de uma traição do que aqui. No nosso caso, no nosso tempo, a autonomia da área, baseada em uma forma de avaliação como descrevi antes, retira as armas do intelectual de influenciar o mundo social.

A consequência, contudo, é que isso mina a própria autonomia de nosso campo. Isso se dá, em primeiro lugar, porque interfere no sistema de consagração. Os intelectuais heterônomos recebem sua legitimidade de outro campo, a partir das regras do campo mediático. Ali consagrados, as regras que os consagram desvalorizam as regras do campo das ciências sociais e, dessa forma, distorcem o campo das ciências sociais. Os intelectuais socialmente mais respeitados eram aqueles que também eram respeitados no próprio campo; hoje os intelectuais mais respeitados socialmente possuem - embora não sempre - pouco lastro dentro do campo das ciências sociais. Em segundo lugar, esses intelectuais heterônomos colocam temas em seus debates na mídia que ressoam os próprios interesses do meio em que estão. Wright Mills (2000, p. 226) tem uma regra de ouro: "não permita que assuntos públicos, como eles são oficialmente formulados, ou problemas, como eles são privadamente sentidos, determinem os problemas que você assumirá para estudar". Em outras palavras, as pesquisas acadêmicas não podem se tornar reféns de perguntas colocadas por campos externos, como a mídia. As ciências sociais precisam manter sua condição de formular suas perguntas, outras das que seriam geralmente formuladas, pois é a própria formulação da pergunta que modifica a forma como vemos o mundo. Se o trabalho intelectual ainda é revelar aquilo que no mundo não se vê, de que na mídia não se fala, ele não pode se reduzir a responder ao que a mídia formula, como os intelectuais heterônomos fazem. Em outras palavras, quanto mais buscam se inserir no debate público, mais os intelectuais se movimentam em um campo mediático, adotando as mesmas perguntas que ali são feitas, adequando suas respostas às expectativas do meio, tornando-se, tristemente, gurus de auto-ajuda.

A outra ameaça se refere ao movimento cada vez mais forte para uma instrumentalização de nossas pesquisas. Nos programas políticos de dois candidatos a presidente, a universidade foi vista simplesmente como espaço de produção de mão de obra para o mercado. No programa de governo do candidato Jair Bolsonaro ${ }^{7}$ (BOLSONARO2018, p. 49), no único trecho que se dedicava à universidade lia-se

\footnotetext{
7 Foi eleito presidente do Brasil pelo Partido Social Liberal (PSL), em outubro de 2018, e tomou posse em janeiro de 2019 .
} 
que: "as universidades, em todos os cursos, devem estimular e ensinar o empreendedorismo. O jovem precisa sair da faculdade pensando em como transformar o conhecimento obtido em enfermagem, engenharia, nutrição, odontologia, agronomia, etc., em produtos, negócios, riqueza e oportunidades." Nas diretrizes gerais do programa do candidato Geraldo Alckmin (2018, p.14), também na única vez em que a universidade era mencionada, afirmava-se: "Vamos estimular as parcerias entre universidades, empresas e empreendedores para transformar a pesquisa, a ciência, a tecnologia e o conhecimento aplicado, em vetores do aumento de produtividade e da competitividade do Brasil".

Confesso que pessoalmente sinto arrepio - talvez eu ressoe aqui Adorno contra Lazarsfeld (POLLACK, 2018), embora eu não me considere assim - quando nossos conhecimentos são utilizados para a reprodução da ordem social. No entanto, não é esse o meu ponto aqui, a questão que coloco é que muitos de nós nos engajamos na sociedade produzindo pesquisas encomendadas, utilitárias. Nesse sentido, tanto faz se as pesquisas administrativas se voltam para o mercado ou para movimentos sociais. Entendo que poder se aliar, estrategicamente, enquanto intelectuais, em pesquisas com as quais se sinta afinidade e que se voltem a fins externos ao campo das ciências sociais seja algo extremamente positivo. Contudo, entendo que tal engajamento não pode ser aquilo que defina a relevância da área. Isso porque se aceitamos que essa é sua relevância, aceitamos que a pesquisa acadêmica só pode ser relevante quando referendada externamente e, então, perdemos a resistência que tínhamos. Digo isso também para dialogar com uma demanda que nós professores e pesquisadores recebemos constantemente. É comum que nossos alunos nos exijam um maior engajamento social, uma maior participação em movimentos sociais, o desenvolvimento de projetos de pesquisa que respondam mais a esses anseios. É quase como se dissessem que nossas pesquisas só têm validade se elas se voltarem para algo socialmente útil. Mal percebem que a base de seus discursos é idêntica a do mercado: uma demanda pela utilidade das pesquisas. Mais uma vez: acho legítimo a todo intelectual, que sentir desejo e necessidade, se engajar nessas batalhas. Pessoalmente - e isso não importa no argumento, mas na necessária sinceridade de propósitos - me sentiria mais a vontade em me engajar com os movimentos sociais, do que com as demandas de mercado. Mas isso tanto faz. O que não pode vir de meu engajamento é a relevância de minha função como intelectual.

$* * *$

Quero argumentar que o mais urgente papel que temos, se quisermos lutar pela autonomia do campo das ciências sociais e fortalecer sua condição de deformar outros campos, é produzir novas armas, diferentes daquelas do sistema de avaliação. 
A avaliação precisa ser repensada em vários termos, mas centralmente ela precisa ser questionada em sua hegemonia como forma de estruturação do campo acadêmico. Tal hegemonia existe e produz efeitos porque está inserida em um sistema de crenças e é isso que deve ser combatido. Nós precisamos reconhecer a que a avaliação se destina e não nos basearmos nela para nada além disso. Não usemos esses índices para o que não seja próprio deles. Somos avaliadores de mesas de congressos, de bolsas, de projetos de pesquisa, somos leitores de artigos, de livros, etc. Que avaliemos pelo que nossos colegas escrevem, pelas pesquisas que fazem, e não pelos pontos que somam. Uma vez separada a avaliação da legitimidade - essa é a questão central - controlamos a força da avaliação sobre nossa produção. Podemos, realmente, aprender a usar as avaliações de outro modo. Por exemplo: por que ao invés de avaliar para ranquear - e, assim, decidir os destinos de recursos - não avaliamos para identificar vocações dos programas, possibilidades de colaborações entre eles, etc.?

Entendida a avaliação em seu lugar, podemos pensar em novas armas para reforçar a autonomia das áreas e ao mesmo tempo a relevância de nossas pesquisas. Aqui poderia encerrar o texto, pois não tenho receitas, mas algo vem ocorrendo nessa direção e encerrar por seu exemplo ilustra o caminho que proponho seguir. Penso nas recentes políticas acadêmicas que buscam ampliar a base social das universidades, tais como as políticas de ações afirmativas. Muito se fala dessas políticas como forma de reparação histórica, representação, benefício para os alunos. Não nego que sejam tudo isso, mas há um outro aspecto que quero destacar: as políticas de ação afirmativa beneficiam a produção intelectual de nosso campo. Isso se dá, em primeiro lugar, por algo que Weber (2016) já pensava: as diferentes visões de mundo possibilitam diferentes perguntas e diferentes propostas de pesquisa. Aqueles que Bourdieu e Passeron (2013) chamariam de não-herdeiros podem produzir novos arbitrários culturais e, assim, estimularem novos debates, levarem colegas e professores a olharem para outros objetos, conhecerem novos autores. É fundamental que tomemos cuidado para não especializarmos os alunos em suas experiências, mas, de fato, criarmos a condição para que alunos e professores troquem conhecimento, que o cânone sociológico se encontre com o novo, que os herdeiros aprendam com os não-herdeiros e os ensinem. Só assim seremos capazes de produzir novas pesquisas e construir novos objetos. Ainda, com uma composição social mais heterogênea, mais representativa da realidade social, nossas pesquisas podem se replicar, alcançando um conjunto maior da sociedade e, assim, se tornarem capazes de influenciar outros campos.

Essas ações nos mostram que para defender a universidade e garantir a autonomia das ciências sociais devemos trazer para dentro do campo o retrato do mundo e desde dentro produzirmos o pensamento capaz de deformar os outros campos da ordem, como a mídia, o mercado, a política e o judiciário. Deixemos 
as avaliações da burocracia em seus lugares, pois o que precisamos produzir não terá qualis.

\section{SOCIAL SCIENCES: BETWEEN EVALUATION AND RELEVANCE}

ABSTRACT: The post-graduation evaluation system implemented in Brazil ensured that scientific research undertaken in Brazilian public universities remained resistant to the threats they frequently suffer. However, the more hegemonic the system became, the more researchers turned the rules into the very notion of scientific relevance, reducing the capacity of social science to influence other fields of knowledge. This work analyses this process and notices how it leads, paradoxically, to the loss of autonomy in the social sciences field due to the importance of the media and the strong demand for more utilitarian research. As a conclusion, it defends the autonomy of the field of social sciences and the public university but by other means, which reallocates their capacity to act in the world, distorting the fields of order.

KEYWORDS: Autonomy. Social sciences. Evaluation system. Scientometry.

\section{CienCIAS SOCIALES: ENTRE EL SISTEMA DE EVALUACIÓN Y LA RELEVANCIA}

RESUMEN: El sistema de evaluación de posgrado, implementado en Brasil, aseguró que la investigación científica llevada a cabo en las universidades públicas brasileñas permaneciera resistente contra las amenazas que sufren con frecuencia. Sin embargo, cuanto más hegemónico se volvió el sistema, más los investigadores convirtieron las reglas en la noción misma de relevancia científica, agotando la capacidad de las ciencias sociales para influir en otros campos del conocimiento. En este artículo analizo este proceso y busco observar la forma en que conduce, paradójicamente, a la pérdida de autonomía de las ciencias sociales debido a la importancia de los medios de comunicación y la demanda por investigaciones más utilitarias. Concluyo defendiendo la autonomía del campo de las ciencias sociales $y$ de la universidad pública, pero por otros medios, que devuelvan su capacidad de actuar en el mundo, distorsionando los campos del orden.

PALABRAS CLAVE: Autonomía. Ciencias sociales. Sistema de evaluación. Scientometría. 


\section{REFERÊNCIAS}

ADLER, Robert; EWING, John; TAYLOR, Peter. Estatísticas de citações. Mediações, Londrina, n. 14, v. 1, p.69-100, 2009.

ADORNO, Sergio; RAMALHO, José Ricardo. A pós-graduação em Sociologia e a experiência de avaliação da CAPES. Revista Brasileira de Sociologia, Brasília, n. 06, vol. 13, p.27-57, 2018.

BALBACHEVSKY, Elizabeth. A pós-graduação no Brasil: novos desafios para uma política bem-sucedida. In: BROCK, C; SCHWARTZMAN, S. Os desafios da educação no Brasil. Rio de Janeiro: Nova Fronteira, p.275-304, 2005.

BOLSONARO2018. Caminho da Prosperidade. Proposta de Plano de Governo. Disponível em: $<$ https://pleno.news/brasil/eleicoes-2018/conheca-o-plano-de-governo-do-candidatojair-bolsonaro.html>. Acessado em 17 mai 2019.

BOURDIEU, Pierre. Sobre a televisão. Rio de Janeiro: Zahar, 1997.

.What makes a social class? On the Theoretical and Practical Existence of Groups.

Berkeley Journal of Sociology, 1987.

. Questões de Sociologia. Rio de Janeiro: Marco Zero, 1983.

BOURDIEU, Pierre; PASSERON, Jean-Claude. Os herdeiros: os estudantes e a cultura. Florianópolis: Editora da UFSC, 2013.

BRASIL. Ministério da Educação. Coordenação de Aperfeiçoamento de Pessoal de Nível Superior - CAPES. Documento de Área: Sociologia, 2017. Disponível em: <www.capes. gov.br/.../documentos/.../20122017-sociologia_relatóriodeavaliação_quad...>. Acessado em: 18 mai. 2019.

. Ministério da Educação. Coordenação de Aperfeiçoamento de Pessoal de Nível Superior - CAPES. Documento de Área: Sociologia, 2016. Disponível em: $<$ https://capes. gov.br/.../documentos/Documentos_de_area.../34_SOCI_docarea_2016.p...>. Acessado em: 18 mai. 2019.

. Ministério da Educação. Coordenação de Aperfeiçoamento de Pessoal de Nível Superior - CAPES. Documento de Área: Sociologia, 2013. Disponível em: $<$ https://capes. gov.br/images/stories/...area/Sociologia_doc_area_e_comissão_21 out.pdf $>$. Acessado em: 18 mai. 2019.

GERALDO ALCKMIN. Programa de Governo. Diretrizes Gerais. Julho de 2018. Disponível em: $<$ https://eleicoes.poder360.com.br/media/planos/geraldo-alckmin.pdf $>$. Acessado em: 17 mai. 2019.

IANNI, Octavio. Teorias da Globalização. Rio de Janeiro: Civilização Brasileira, 2006. 
. As ciências sociais na época da globalização. Revista Brasileira de Ciências Sociais, n.13, vol. 37, p.1-8, 1998.

LODGE, David. Small World. In: . The Campus Trilogy. London: Penguin Books, p.207-534, 2011.

MARTINS, Carlos Benedito. O ensino superior brasileiro nos anos 90. São Paulo em perspectiva, São Paulo, v. 14, n.1, Jan/Mar. p.41-60, 2000.

MARTUCCELLI, Danilo. Crítica da Filosofia da Avaliação. In: BALANDIER, GEORGES. O que avaliar quer dizer? São Paulo: Editora FAP-Unifesp, p.37-65 2015.

MORAES, Fernando Tadeu. Brasil aumenta produção científica, mas impacto nos trabalhos diminui. FOLHA DE S. PAULO. São Paulo, 16 de outubro de 2017. Disponível em: $<$ https://www1.folha.uol.com.br/ciencia/2017/10/1927163-brasil-aumenta-producaocientifica-mas-impacto-dos-trabalhos-diminui.shtml.>. Acessado em: 18 mai 2019.

ORTIZ, Renato. Internationalization of the Social Sciences. Sociologies in Dialogue, n. 2, vol. 1, p.31-45, 2016.

Cientificidade, cientometria e insensatez. In: ORTIZ, Renato. A Diversidade dos

Sotaques (o inglês e as ciências sociais). São Paulo: Brasiliense, p.135-188, 2008.

POLLACK, Michael. Paul F. Lazarsfeld: fundador de uma multinacional científica. Política \& Sociedade, vol. 17, n. 38, p.94-134, 2018.

SARTI, Cynthia. O “inavaliável”. In: BALANDIER, GEORGES, O que avaliar quer dizer? São Paulo: Editora FAP-Unifesp, p.9-12, 2015.

SILVA, Antonio Ozaí da. A sua revista tem qualis? Mediações, Londrina, n. 14, v. 1, p.117-124, 2009.

TOLEDO, Luiz Fernando e MARQUES Júlia. Universidades federais têm menos de 1\% de intercambistas estrangeiros. O Estado de S. Paulo. São Paulo, 19 de junho de 2018. Disponível em: $<$ https://educacao.estadao.com.br/noticias/geral,universidades-federais-temmenos-de-1-de-intercambistas-estrangeiros,70002355154>. Acessado em: 19 mai. 2019.

WEBER, Max. A "objetividade" do conhecimento na ciência social e na ciência política. In: Metodologia das Ciências Sociais. São Paulo: Cortez, 2016.

WRIGHT MILLS, Charles. The sociological imagination. Oxford: Oxford University Press, 2000.

Recebido em 06/03/2019.

Aprovado em 06/04/2019. 